\title{
Mercado y consumo: economía política de las telecomunicaciones en Colombia
}

Market and consumption: political economy of telecommunications in Colombia

\author{
Ancizar Narváez Montoya \\ Doctor en Educación, Universidad Pedagógica Nacional \\ anarvaez@uni.pedagogica.edu.co
}

Artículo de investigación

Fecha de recepción: 7 de octubre de 2011 • Fecha de aprobación: 3 de noviembre de 2011

\section{RESUMEN}

Con base en los estados financieros reportados por las principales empresas de telecomunicaciones y radiodifusión de Colombia, se muestra la concentración de la oferta y a la centralización de la propiedad, así como una jerarquización de los sectores involucrados, según su importancia económica. Adicionalmente, con base en el estudio general de medios, EGM, del segundo semestre de 2010, se pondera la importancia política de cada sector de telecomunicaciones; esto es, la infraestructura y la radiodifusión en cuanto a su contribución en la esfera pública.

Palabras clave: Colombia, telecomunicaciones, radiodifusión, mercado, consumo mediático.

\section{Abstract}

Based on financial statements reported by the main media and radio companies in Colombia, this article demonstrates supply and property concentration, as well as the existence of a hierarchy of sectors involved, according to their economic relevance. Additionally, based on a general media study -EGM- of the second semester of 2010, the article assesses the political importance of each sector in telecommunications: this is, infrastructure, radio diffusion and their contribution to the public sphere.

Keywords: Colombia, telecommunications, broadcasting, market, media consumption. 


\section{INTRODUCCIÓN}

Hablar de economía política de la comunicación en una aproximación tan breve y tan modesta puede parecer pretencioso, puesto que no se abordan en rigor las relaciones capital-trabajo en las comunicaciones, el monto de la plusvalía y la distribución del valor; pero si tenemos en cuenta la siguiente observación de Golding y Murdock (2000), es posible afirmar que algunos de estos temas sí se abordan, aunque someramente:

[La economía política crítica] difiere de la corriente económica principal en cuatro aspectos centrales: primero, es holística; segundo, es histórica; tercero, está interesada principalmente en el balance entre empresa capitalista e intervención pública; y finalmente —y tal vez lo más importante de todo—, va más allá de los asuntos técnicos de la eficiencia para involucrarse en las cuestiones morales básicas de la justicia, la equidad y el bien público (pp. 72-73).

En este caso no solo se aborda el problema de la estructura de la propiedad, la relación entre Estado y empresa privada, y el grado de centralización de la propiedad y de concentración de la oferta y control del mercado, sino también la relación entre capital extranjero y capital nacional y, por tanto, la manera como se sitúa Colombia en la relación centro-periferia del sistema.

Metodológicamente, se trata, en primer lugar, de delimitar en forma amplia el concepto de telecomunicaciones, incluyendo no solo la telefonía e internet, sino también el sistema de radiodifusión del país (radio y televisión); en segundo lugar, se intenta una aproximación a la estructura de propiedad en cada sector; en tercer lugar, teniendo en cuenta las cifras de ventas y a veces de utilidades, se intenta establecer la jerarquía entre los diferentes sectores, dada su importancia económica y política.

Por otro lado, se trata de establecer la estructura del consumo mediático, para determinar la importancia política y cultural de los diferentes medios y, al mismo tiempo, definir la participación de la oferta pública y privada en ese consumo, de tal suerte que se pueda identificar no solo el tamaño de la esfera pública mediática (cuántos agentes están en juego), sino además la importancia de cada agente y, por tanto, la orientación democrática o totalitaria de aquella. 
En mi texto Puentes tecnológicos, abismos sociales había mostrado cómo el régimen de acumulación de la economía informacional se basaba en la jerarquía que se establece entre sus diferentes subsectores industriales (Narváez, 2002, pp. 92-93). Dicha jerarquía parte de las empresas de infraestructura de telecomunicaciones y termina con las empresas propia y exclusivamente de internet, pasando por las empresas de la industria cultural o productoras de contenido, siguiendo con las de hardware informático (procesadores y sistemas operativos), como se muestra en la siguiente tabla.

Tabla 1. Convergencia económica en internet

\begin{tabular}{|c|c|c|c|c|c|c|}
\hline $\begin{array}{l}\text { Telecomuni- } \\
\text { caciones }\end{array}$ & Convergencia & $\begin{array}{c}\text { Industria } \\
\text { cultural }\end{array}$ & Convergencia & Informática & Convergencia & Internet \\
\hline Telefonía fija & $\begin{array}{l}\text { Televisión } \\
\text { por cable }\end{array}$ & $\begin{array}{l}\text { Televisión, } \\
\text { radio, } \\
\text { impresos }\end{array}$ & CD-Rom & Procesadores & Navegadores & $\begin{array}{c}\text { Manejo } \\
\text { de dominios }\end{array}$ \\
\hline \multirow[t]{3}{*}{ Telefonía móvil } & $\begin{array}{c}\text { Televisión } \\
\text { satelital }\end{array}$ & $\begin{array}{l}\text { Cine-video, } \\
\text { discos }\end{array}$ & DVD & Hardware & Protocolos & Dominios \\
\hline & & $\begin{array}{c}\text { Espectáculos, } \\
\text { publicidad }\end{array}$ & Videojuegos & Software & & Servidores \\
\hline & & & & Datos & & $\begin{array}{c}\text { Sitios, } \\
\text { motores } \\
\text { de búsqueda, } \\
\text { portales }\end{array}$ \\
\hline
\end{tabular}

Fuente: Narváez (2002)

Como sector intermedio entre las primeras y las segundas encontramos la industria de la televisión cerrada (satelital y por cable), que no es en rigor productora de contenido, sino una manera de circulación de los productos en forma de servicios. Entre las segundas y las terceras encontramos la industria de los juegos electrónicos, el DVD y el CD, también maneras de circular los productos culturales en forma de bienes y no de servicios. Finalmente, entre las terceras y las cuartas se hallan todos los software y protocolos que permiten la navegación y la existencia de la red como espacio de interactividad.

Esta jerarquía se basa en su importancia económica y política. Entre la infraestructura y la producción de contenido se debaten las jerarquías en Colombia, es decir, se decide cuál es el sector más rentable y, por tanto, de mayor acumulación. 


\section{LAS EMPRESAS DE TELECOMUNICACIONES Y EL MERCADO NACIONAL}

\section{Infraestructura}

Habrá que diferenciar la infraestructura de telecomunicaciones de la infraestructura de radiodifusión, o broadcasting, pues aunque en rigor ambas son telecomunicaciones, la primera no implica contenidos adheridos a su naturaleza, mientras que la razón de ser de la segunda es justamente la transmisión de contenidos. En ese sentido, la infraestructura de telecomunicaciones tiene un valor estratégico en términos económicos, políticos y de soberanía (hacia dentro, porque es presencia física del Estado, y hacia fuera, porque marca independencia y control del territorio), más que un valor cultural. Sin embargo, la radiodifusión no puede existir sin una infraestructura de telecomunicaciones que la soporte; en consecuencia, aquí se incluyen ambas.

Con la venta de Telecom en 2004 se quebró lo que debía ser un monopolio natural, es decir, una sola red de telecomunicaciones encabezada por Telecom que administrara tanto la conexión satelital como el espectro electromagnético a través de las diferentes estaciones terrestres. Técnicamente, se supone que Telecom debería ofrecer el soporte tanto para la telefonía fija, en caso de ingresar otros operadores (como lo hicieron Orbitel y ETB a partir de 1997), como para la telefonía móvil. Asimismo, debía ofrecer los servicios satelitales a Inravisión, instituto cuya función radiodifusora podría, a su vez, extenderse a la operación de los canales privados de televisión, en caso de hacerse la concesión (como efectivamente se hizo).

Sin embargo, lo que hoy tenemos es una infraestructura segmentada en varias redes independientes. Por un lado, para las telecomunicaciones tenemos la red matriz de Telecom, cuyo cubrimiento nacional le permite precisamente ser matriz de los otros dos operadores de telefonía fija, además de las tres redes independientes de los operadores móviles: Comcel, Telefónica y Colombia Móvil; por otro lado, para la radiodifusión tenemos la red pública de la Radio Televisión de Colombia (RTVC), que sirve a los tres canales públicos de alcance nacional y a los ocho regionales, además de la red privada nacional administrada por el consorcio RCN y Caracol Televisión. 
En primer lugar, esta situación resulta económicamente irracional, pues una sola infraestructura podría cumplir la función de las cinco; en segundo lugar, desde el punto de vista político es inconstitucional y arriesgada para la seguridad nacional, pues en la práctica, el control del espectro y de la infraestructura terrestre está en manos de agentes privados y extranjeros.

En efecto, desde el punto de vista de la pura economía, la situación colombiana se caracteriza por dos fenómenos: por un lado, el cuasimonopolio de los extranjeros; por otro, el cuasimonopolio de los poseedores de redes. Así, en Colombia, según la Superintendencia de Sociedades, existen sesenta empresas de telecomunicaciones por lo menos entre las cinco mil más grandes del país. Sin embargo, la concentración en este sector es enorme: de los 22 billones 21.000.631 millones de pesos (U\$ 11.917,3 millones) facturados en $2009^{1}$, equivalentes aproximadamente al 5,5\% del producto interno bruto (PBI) de Colombia, las primeras ocho concentraron 14 billones 934.000.877 millones (U\$ 7.864,6 millones), es decir, el 67,8 \% (tabla 2).

Por otro lado, entre estas ocho empresas, la mayoría son privadas (cinco); sin embargo, la mayor concentración se da en términos de propietarios: Comcel y Télmex Colombia son en realidad la misma empresa (Télmex, hoy Claro), lo cual quiere decir que ella sola factura 6 billones 947.000 .642 millones de pesos, o sea, aproximadamente el 1,75 \% del PIB de Colombia en un año. Lo mismo puede decirse de Telefónica y Colombia Telecom, pues son ambas de Telefónica España. Su facturación de 3 billones 823.000.207 millones (U\$ 2.013,27 millones) equivale casi al 1,0 \% de PIB. Es decir, más de 2,5\% del PIB de Colombia pasa por las manos de dos empresas extranjeras de telecomunicaciones.

Finalmente, Orbitel es el operador de larga distancia de EPM y ETB; o sea, en realidad tenemos dos empresas públicas en vez de tres. En síntesis, tenemos dos empresas públicas y tres empresas privadas en el mundo de las telecomunicaciones, pero mientras las privadas tienen el negocio de la telefonía celular y compiten en el de la telefonía fija, las públicas son vanguardia en la fija, pero no compiten en el sector del futuro, que es

1 Se calcula con precio promedio del dólar en 2010, que fue de 1.899 pesos por dólar (www.preciodeldolar. com.co). 
la telefonía móvil. Pero lo más destacable es que lo que les permite a estas empresas ser las líderes de la telefonía es que poseen la infraestructura física de redes y torres, lo que les posibilita no solo ser operadores sino también propietarios y productores (tabla 2).

Tabla 2. Principales operadores de telecomunicaciones por ventas y utilidades

\begin{tabular}{lcccc}
\hline \multicolumn{1}{c}{ Empresa } & $\begin{array}{c}\text { Ventas } \\
\text { (millones de \$) }\end{array}$ & $\begin{array}{c}\text { Ventas } \\
\text { (millones de U\$) }\end{array}$ & $\begin{array}{c}\text { Utilidades } \\
\text { (millones de \$) }\end{array}$ & $\begin{array}{c}\text { Utilidades } \\
\text { (millones de U\$) }\end{array}$ \\
\hline Comcel & 5.849 .180 & $3.080,13$ & $1,209,964$ & 637,15 \\
\hline Colombia Telecom & 2.041 .075 & $1.074,81$ & $-341,946$ & $-180,06$ \\
\hline Telefónica Móviles & 1.782 .132 & 938,45 & $-572,148$ & $-301,29$ \\
\hline UNE (EPM-Telco) & 1.525 .940 & 803,54 & 120.298 & 63,34 \\
\hline ETB & 1.437 .700 & 757,08 & 202.957 & 106,87 \\
\hline Télmex Colombia & 1.108 .062 & 583,49 & -19.586 & $-10,31$ \\
\hline Colombia Móvil & 845.550 & 445,26 & -50.356 & $-26,51$ \\
\hline Orbitel (servicio internacional) & 345.238 & 181,79 & -141 & $-0,07$ \\
\hline Total & 14.934 .877 & $7.864,60$ & 549.042 & 289,12 \\
\hline
\end{tabular}

Fuente: cálculos del autor con base en la revista Dinero (2010, p. 296)

\section{Televisión}

En cuanto al negocio de la televisión, hay que tener en cuenta que esta es a la vez una tecnología y una narrativa, una empresa y una institución. En consecuencia, se deben distinguir tres clases de agentes: los que tienen producción e infraestructura de difusión, los que tienen solo producción y los que tienen solo redes. Como negocio, hay que tener en cuenta que las que funcionan como tales son, formalmente, los operadores con ánimo de lucro; pero, informalmente, las televisiones locales y comunitarias son pequeños negocios que no alcanzan a estar registrados en la Superintendencia de Sociedades. Sin embargo, el grueso del negocio está en los primeros.

En efecto, aunque la Superintendencia de Sociedades incluye todos los tipos de empresa como televisión, sobre todo por el papel que desempeñan en la financiación de la televisión pública, de las trece empresas que clasifican entre las cinco mil más grandes del país, podemos hacer la siguiente discriminación: 
1. Empresas con producción y frecuencia: Quiere decir que tienen canal propio o tienen espacios en concesión en el canal (un espacio) y, por tanto, son responsables de su propia programación (tabla 3). Las que tienen canal propio son responsables, además, del flujo.

Tabla 3. Televisión (programadoras, productoras y difusoras)

\begin{tabular}{lcccc}
\hline \multicolumn{1}{c}{ Empresa } & $\begin{array}{c}\text { Ventas } \\
\text { (millones de } \mathbf{\text { }})\end{array}$ & $\begin{array}{c}\text { Ventas } \\
\text { (millones de U\$) }\end{array}$ & $\begin{array}{c}\text { Utilidades } \\
\text { (millones de \$) }\end{array}$ & $\begin{array}{c}\text { Utilidades } \\
\text { (millones de U\$) }\end{array}$ \\
\hline RCN Televisión & 464.613 & 244,66 & 25.113 & 13,22 \\
\hline Caracol Televisión & 446.696 & 235,22 & 22.790 & 12,00 \\
\hline Teleantioquia & 28.345 & 14,92 & 2431 & 1,28 \\
\hline CEETTV (City Tv) & 25.437 & 13,39 & -5134 & $-2,70$ \\
\hline CM\& Televisión & 19.093 & 10,05 & 2516 & 1,32 \\
\hline Total & 984.184 & 518,26 & 47.776 & 25,15 \\
\hline
\end{tabular}

Fuente: revista Dinero (2010)

2. Empresas productoras: Estas suelen producir para las anteriores y, eventualmente, para los canales que se ofrecen por las empresas de televisión cerrada. No son responsables de la programación ni del flujo (tabla 4).

Tabla 4. Televisión (empresas productoras)

\begin{tabular}{lcccc}
\hline \multicolumn{1}{c}{ Empresa } & $\begin{array}{c}\text { Ventas } \\
\text { (millones de } \mathbf{~})\end{array}$ & $\begin{array}{c}\text { Ventas } \\
\text { (millones de U\$) }\end{array}$ & $\begin{array}{c}\text { Utilidades } \\
\text { (millones de } \mathbf{~})\end{array}$ & $\begin{array}{c}\text { Utilidades } \\
\text { (millones de U\$) }\end{array}$ \\
\hline RTI & 51.471 & 27,0 & 5384 & 2,83 \\
\hline Teleset & 51.250 & 26,98 & -1384 & $-0,73$ \\
\hline Fox Telecolombia & 50.010 & 26,33 & 4179 & 2,20 \\
\hline Coltevisión & 28.900 & 15,21 & 887 & 0,47 \\
\hline Vista Productions & 25.093 & 13,21 & 690 & 0,36 \\
\hline Total & 206.724 & 108,85 & 9756 & 5,13 \\
\hline
\end{tabular}

Fuente: revista Dinero (2010)

* Tasa promedio de 1.899 pesos colombianos por dólar (2010). 
3. Empresas difusoras: Solo poseen la infraestructura, no son responsables de la producción, ni de la distribución, ni del flujo. Tienen la obligación de producir y programar un canal propio dentro de la oferta, especialmente informativo (tabla 5).

Tabla 5. Televisión (empresas difusoras)

\begin{tabular}{lcccc}
\hline \multicolumn{1}{c}{ Empresa } & $\begin{array}{c}\text { Ventas } \\
\text { (millones de \$) }\end{array}$ & $\begin{array}{c}\text { Ventas } \\
\text { (millones de U\$) }\end{array}$ & $\begin{array}{c}\text { Utilidades } \\
\text { (millones de \$) }\end{array}$ & $\begin{array}{c}\text { Utilidades } \\
\text { (millones de U\$) }\end{array}$ \\
\hline DirectTv Colombia & 116.686 & 61,44 & -42.056 & $-22,14$ \\
\hline Cable Unión Occidente & 53.691 & 28,27 & 145 & 0,80 \\
\hline $\begin{array}{l}\text { Supercable } \\
\text { Telecomuniciones }\end{array}$ & 17.551 & 9,24 & -3178 & $-1,67$ \\
\hline \begin{tabular}{l} 
Total $^{*}$ \\
\hline
\end{tabular} & 187.928 & 98,96 & -45.089 & $-23,74$ \\
\hline
\end{tabular}

Fuente: revista Dinero (2010)

*Aquí no aparecen los datos de Télmex Hogar, que tiene más de 1.700 .000 abonados y facturó en 2008 más de 600.000 millones de pesos; el 2009 parece haber consolidado esa facturación con Télmex Colombia. Tampoco aparecen los de UNE-EPM, con algo más de 700.000, ni los de Telefónica Colombia, porque aparecen como agregados a los de telefonía e internet en las empresas de telecomunicaciones.

Como se puede ver en cifras (tablas 3, 4 y 5), el negocio de la televisión en términos de producción y programación no es el más rentable. Las ventas de todos los operadores aquí registrados suman, en 2009, alrededor de 1 billón 300.000 millones de pesos (684,5 millones de dólares), lo cual no alcanza a ser sino aproximadamente el 0,3\% del PIB del país. Desde luego que el grueso de la facturación está en los grandes operadores de televisión por cable, que, como ya se vio, son Télmex, Telefónica, UNE-EPM y ETB; pero, entonces, su negocio son las redes, la infraestructura, y por eso existen primero que todo como empresas de telecomunicaciones.

En cuanto a la televisión pública, existen cuatro modalidades de financiación universales: el canon, el presupuesto público, la publicidad y la tarifación. En Colombia, esta se financia, por ley, de las siguientes fuentes:

1. Televisión abierta: De estos operadores se obtienen el valor de la concesión, desde luego por una sola vez, y el 1,5\% de los ingresos brutos como ingreso permanente. 
Esta es la única fuente verificable y calculable. Según las cifras vistas aquí, en 2009 los tres canales privados sumaron ingresos por aproximadamente 950.000 millones de pesos (500,3 millones de dólares), lo cual significa ingresos para la televisión pública de unos 13.500 millones de pesos (U\$ 7,1 millones).

2. Televisión cerrada: De aquí se obtienen el valor de la concesión o derecho de entrada y el 10\% de los ingresos brutos por las suscripciones, así como el 10\% de la facturación por publicidad del canal propio que debe programar cada concesionario. Con las cifras que tenemos en la tabla 2 y con la facturación de Télmex Hogar de 2008, la única cifra cierta que tenemos son los \$615.177 millones que facturó por sus más de 1.700 .000 afiliados, más los \$ 187.928 de los restantes operadores, es decir, cerca de 800.000 millones (U\$ 423,2 millones) (revista Dinero, 29 de mayo de 2009).

En cálculos proporcionales, si en 2008 UNE-EPM tenía 739.260 suscriptores de televisión cerrada, DirectTv (ETB) tenía 214.830 y Colombia Telecomunicaciones (Telefónica) 132.808, estamos hablando de casi 1.100 .000 suscriptores entre los otros tres operadores, lo que significaría una facturación aproximada de 390.000 millones de pesos (U\$ 205,3 millones). En total, estaríamos llegando a una suma cercana a 1 billón 200.000 millones (U\$ 631,9 millones). En consecuencia, deberían pagar a la Comisión Nacional de Televisión unos 120.000 millones (U\$ 63,2 millones).

3. Televisión comunitaria: El 7\% que debería recibir por los pagos de los afiliados de los canales comunitarios es casi imposible de calcular. Con la cantidad de canales comunitarios existentes, casi 700, los que como mínimo debían tener 200 afiliados, estaríamos hablando de por lo menos 100.000 afiliados. Pero ya vimos que el promedio de afiliados es de 15.000 o más, o sea, más de 7 millones de afiliados, lo que convertiría a esta modalidad de televisión en la principal fuente de financiación de la televisión pública; sin embargo, la precariedad económica en que sobreviven y el hecho de ser realmente negocios particulares les impide reportar la cantidad real de afiliados para evadir estos pagos. Esta es más o menos la regla.

Si la televisión pública se compone de tres canales nacionales y ocho canales regionales, esto quiere decir que con la cuarta parte de los ingresos de uno solo de los canales privados tendríamos que hacer funcionar once canales públicos. ¿Habrá alguna posibilidad de competir? 


\section{La radio}

El negocio de la radio se presume como uno de los más rentables en el país, pero la información al respecto es también de las más opacas. Lo primero que hay que recalcar es que su gran dispersión hace difícil saber el agregado de ingresos o de ventas que realizan los miles de operadores de todas las modalidades en el país. En consecuencia, hay que conformarse con los datos sobre los agentes más formalizados, como las grandes cadenas de alcance nacional o los concesionarios de frecuencias comerciales. Aun así, el acceso es restringido.

En efecto, hemos visto que hay más de 600 concesionarios de radios comunitarias. $\mathrm{Su}$ financiación es un completo misterio, pues cada concesionario parece ser un empresario, un gestor o lo que sea; pero no está claro en ningún registro estatal cuántos son los ingresos y de dónde provienen. En cuanto a las radios de interés público, no está cuantificado tampoco el valor total de los presupuestos asignados a cada emisora por la institución que usufructúa la concesión. En el caso de las radios universitarias, tampoco hay aún algún ente que haya desagregado, en el presupuesto de las universidades, lo asignado a las emisoras ni, mucho menos, cuánto suman estos presupuestos juntos.

Así las cosas, nos quedan solamente las cuentas de las empresas dedicadas a la radio comercial. En este caso, hay un número cercano a 200 concesionarios, de los cuales solo los más grandes, esto es, unos 42, reportan estados financieros a la Superintendencia de Sociedades. El monto de los ingresos de estos 42 operadores es una tarea pendiente. De estos, solo tienen información pública los 3 más grandes ya mencionados, por cuanto se clasifican entre las 5.000 empresas más grandes de Colombia; es decir, entre las 5.000 empresas solo hay 3 radiales y únicamente 2 entre las primeras 1.000, medidas por sus ingresos: Caracol Radio, que facturó \$ 140.000.682 millones (U\$ 74,1 millones); RCN Radio, que facturó \$ 140.000.408 millones (U\$ 73,9 millones), y, muy lejos de las anteriores, la Organización Radial Olímpica, que facturó \$34.000.663 millones (U\$ 18,2 millones) en 2009, una cuarta parte de la facturación de las anteriores (revista Dinero, 2010).

En cuanto a las utilidades, las 42 empresas radiales que reportaron en 2009 a la Superintendencia de Sociedades sumaron ganancias por \$ 59.000 .062 millones; pero de 
esas utilidades, solo 3 empresas (RCN, Caracol y Radio Continental) se quedaron con \$53.000.721 millones (U\$ 28,3 millones), o sea, el $91 \%$ de las ganancias (Superintendencia de Sociedades, 2010). No es necesario hacer comentarios adicionales sobre la situación oligopólica del mercado de la radio en Colombia; no hay manera, por ahora, de cuantificar su contribución al PIB en tanto no se conozcan sus ventas totales.

\section{El consumo, la audiencia y la nación}

$\mathrm{Si}$, como se ha visto, la televisión, como producción y como programación, no es el gran negocio, el cual se halla mejor remunerado en la circulación a través de la infraestructura de telecomunicaciones, entonces, ¿cuál es la razón para que haya tanto interés en acceder a frecuencias, a nuevos canales, etc.? La explicación puede estar en el hecho de que es el medio con mayor audiencia en el país y, por tanto, en el que mejor se pueden legitimar los distintos relatos de la nación. Según el Estudio General de Medios (EGM, 2010-II), las audiencias en Colombia se distribuyen como sigue (tabla 6):

Tabla 6. Medios y audiencias en Colombia*

\begin{tabular}{ll}
\hline Medio & $\begin{array}{l}\text { Audiencia } \\
\text { (EGM, 2010-II) }\end{array}$ \\
\hline Televisión & 94,7 \\
\hline Radio & 64,7 \\
\hline Revistas independientes & 42,8 \\
\hline Prensa & 33,3 \\
\hline Internet & 35,9 \\
\hline Revistas prensa & 21,0 \\
\hline Cine & 5,9 \\
\hline
\end{tabular}

Fuente: CNTV (2010b), ACIM, EGM

*Las audiencias de los medios se midieron así: televisión, espectadores por día; radio, oyentes por día; revistas independientes y de prensa, lectores por periodo de publicación; prensa e internet, usuarios por día; y cine, espectadores por semana.

Aquí se presenta la primera muestra cultural protuberante de las características de la nación: consiste en que el consumo de medios es descendente en la medida en que los medios son más alfabéticos, o en la medida en que exigen erogaciones económicas. Si la televisión es el medio nacional por excelencia, el que fija la agenda y el que 
reúne las características culturales más populares (oralidad, iconicidad y narrativa), no tiene nada de extrańo que sea el medio por excelencia de una sociedad poco alfabetizada (tevecéntrica en vez de diariocéntrica). Asimismo, la radio, además de las características narrativas orales, tiene una característica adicional que viene con la oralidad: en ella se logran identificar las hablas regionales.

Pero, ¿qué decir de las revistas independientes? Empecemos por el ranking de estas (tabla 7). Según esta clasificación, hay que hacer, en primer lugar, un poco de justicia con Semana, pues aunque la medición se hace por edición, no es lo mismo una edición semanal que una quincenal o mensual. Para equiparar la lecturabilidad, tendríamos que ponerlas a todas en el mismo lapso de tiempo. Esto significa que, en realidad, quincenalmente esta revista tendría 2.036.000 lectores y, por tanto, sería la primera revista del país, como efectivamente lo es.

Ahora bien, hecha esta salvedad, busquemos los factores culturales. Aunque parezca sorprendente que un medio supuestamente alfabético como las revistas tengan más audiencia que los periódicos e internet, se puede aventurar una hipótesis: vistas las primeras diez revistas del ranking, estas no son en rigor alfabéticas, sino icónicas; no son analíticas, sino narrativas, y en general no requieren competencias alfabéticas para ser consumidas.

Tabla 7. Revistas independientes según lecturabilidad

\begin{tabular}{lc}
\hline Revista & Lecturabilidad \\
\hline TVy Novelas (quincenal) & $1.265,9$ \\
\hline Soho (mensual) & $1.130,9$ \\
\hline Semana (semanal) & $1.018,6$ \\
\hline 15 Minutos (mensual) & 912,0 \\
\hline Cromos (quincenal) & 805,0 \\
\hline Caras (quincenal) & 693,7 \\
\hline Coomeva (bimestral) & 525,9 \\
\hline Vanidades (quincenal) & 515,7 \\
\hline Tú (mensual) & 448,9 \\
\hline National Geographic en Español (mensual) & 447,5 \\
\hline
\end{tabular}

Fuente: EGM, 2010 
Tal vez lo más problemático sea confrontar tal hipótesis con el caso de Semana; sin embargo, en tanto los principales personajes mediáticos, por su condición de poderosos y exitosos, son los gobernantes y los políticos, esta revista lo que hace es prolongar el protagonismo de los mismos personajes en un documento menos efímero. Es decir, quien ve televisión y escucha la radio sabe de qué está hablando Semana. Es una prolongación de la cultura mediática en un medio impreso.

El caso de Coomeva sugiere una revista especializada para afiliados, que no se vende en el mercado, de circulación restringida, con una baja frecuencia en comparación con las demás y, por tanto, no comparable en ningún sentido.

En cambio, las siete siguientes sí tienen una característica en común: son revistas típicas de farándula, es decir, en donde salen los mismos personajes que pueblan la más extendida cultura mediática: la del entretenimiento. Por lo mismo, son demasiado icónicas, demasiado narrativas $y$, a veces, orales; por tanto, no solo son una prolongación de la cultura mediática de la farándula, sino que, en rigor, ni siquiera se necesita saber leer para consumirlas, pues la identidad entre personajes televisivos y de revista hace al televidente absolutamente competente para leer el relato impreso en ellas.

En cuanto a la revista National Geographic en Español, no hay que engañarse con su origen ni con su nombre. Esta no es una revista científica, sino periodística; allí no aparecen artículos científicos, sino más bien relatos de viajes; y no funge como una guía investigativa, sino casi como una guía turística. En rigor, su discurso es más icónico-narrativo que alfabético-analítico. En consecuencia, no hay que extrańarse de su popularidad, pues en términos de competencias exigidas es bien popular.

Más allá de las características de las revistas independientes, su consumo está rigurosamente estratificado, pasando del $25 \%$ en el estrato 1 , al $80 \%$ en el estrato 6 , con una correspondencia exacta entre estrato y consumo cuantitativo. No está claro cuáles son las revistas que consume cada estrato.

En cuanto al consumo de prensa e internet, que comparten más o menos la misma audiencia (una tercera parte de los usuarios), se podría aventurar que comparten también dos características: tienen un origen cuasialfabético, es decir, gráfico: una 
amalgama entre alfabetismo y diseño; y al mismo tiempo son medios de pago (por compra y por tarifación, respectivamente). Además de eso, son hoy el punto de encuentro entre la circulación individual y en línea.

El cine, por su parte, como sustancia y como institución, siempre ha sido minoritario, no solo por los costos, sino que ahora, con la facilidad de ver las películas en televisión, internet o en DVD, etc., su consumo se hace más un asunto social y de prestigio que de posibilidades técnicas o económicas.

Ahora bien, si la oferta es predominantemente oral-icónica, más exactamente televisiva, ¿quién tiene mayor sintonía con la audiencia? Pues bien, esa audiencia se distribuye como muestra la siguiente tabla.

Tabla 8. Audiencia del último mes (noviembre de 2010) en canales nacionales, regionales y locales

\begin{tabular}{lc}
\hline Canal & Audiencia \\
\hline RCN & 89,1 \\
\hline Caracol & 86,8 \\
\hline City TV & 32,3 \\
\hline Señal Colombia & 18,1 \\
\hline Canal 1 & 16,2 \\
\hline Teleantioquia & 15,3 \\
\hline Canal 13 (Andina) & 15,0 \\
\hline Telecaribe & 11,1 \\
\hline Canal Capital & 10,5 \\
\hline Telepacífico & 8,4 \\
\hline Telemedellín & 5,7 \\
\hline Canal Institucional & 4,2 \\
\hline TRO & 3,8 \\
\hline Telecafé & 3,0 \\
\hline
\end{tabular}

Fuente: CNTV (2010b), EGM 2010-II, módulo de televisión 2009-II a 2010-II

Tal vez valga la pena aclarar que este estudio se hace sobre un universo nacional de más de 16 millones de personas mayores de 12 años, en más de 50 ciudades y municipios. 
Con esto se quiere ponderar que las audiencias son de carácter nacional, y por tanto la significación de la más pequeña audiencia, que es la de Telecafé, es muy distinta regionalmente, teniendo en cuenta que ello implica unas 480.000 personas mayores de 12 años en una región que tiene alrededor de 2 millones de habitantes.

Lo que indican estas cifras es que los canales privados nacionales están llegando a más de 14 millones de personas diariamente, y CityTV a unos 5 millones aproximadamente. Estos son los canales de tres de los más grandes grupos económicos del país; es decir, son de empresarios y son empresas; son los voceros del capital; es el capital dirigiéndose a la sociedad.

Entre tanto, los canales públicos nacionales, en conjunto, suman un 38,3\% de la audiencia, lo cual significa más de 6 millones de personas. Esta no es una audiencia para nada desdeñable, teniendo en cuenta las precarias condiciones de financiación que vimos en el apartado anterior. Esta, se supone, es la voz del Estado y del interés común (interés público). Pero si a ello le sumamos las audiencias de los canales regionales, llegamos a una audiencia del 70\%, lo cual significa que el mensaje del Estado a la sociedad llega por lo menos a 10 millones de personas, aunque sea de forma fragmentada entre nacional, regional y local. Si esto se logra con una financiación prácticamente diez veces inferior a la financiación (según ventas) de los canales privados, es posible pensar que con una apuesta seria por la televisión pública sería posible tener versiones de nación alternativas a las exclusivas del capital.

Otro dato por tener en cuenta es que en cada una de las capitales sedes de los canales regionales -excepto en Manizales, donde Telecafé ocupa el cuarto lugar-, el canal regional es el más visto después de RCN y Caracol; es decir, Teleantioquia, Telepacífico, Telecaribe, TRO y Telecafé son parte de la esfera pública regional en mayor medida que los canales públicos nacionales (CNTV, 2010b). Ello significa que sí tienen legitimidad como instituciones.

¿Cuáles son las posibilidades de contrarrestar esta visión tevecéntrica de la sociedad y, más aún, esta visión mistificadora de los medios privados que quieren hacer aparecer intereses corporativos como intereses comunes? Desafortunadamente, el comportamiento de las audiencias no da mucha esperanza. Si bien la audiencia de los medios públicos indica que estos, como lenguajes y como relatos, son maneras 
de contraponer visiones excluyentes, las versiones de la televisión no son confrontables solo ni principalmente desde la misma televisión, sino desde otras alternativas culturales críticas. Para eso sería necesario que el consumo de televisión fuera equiparable con otros medios; sin embargo, las cifras son desalentadoras (tabla 9). Esta estratificación del consumo mediático nos sugiere algunas ideas, no por obvias menos interesantes.

Aunque la televisión y el cine parecieran hablar el mismo lenguaje (imágenes en movimiento, relatos, sonido, música, escenografía, dramaturgia, etc.), se encuentran en los extremos del consumo cultural. El más elitista es el cine, y el más popular es la televisión. Podríamos decir que la asistencia al cine ha dejado de ser un consumo mediático, es decir, un consumo para informarse o divertirse, y se ha convertido en un consumo artístico y, por consiguiente, distinguido. La distancia entre el estrato seis y el uno es de nueve a uno en cuanto a consumo, y la distancia entre los estratos altos y bajos es de siete veces.

Tabla 9. Consumo de medios por estrato social

\begin{tabular}{lcccccc}
\hline Medio & Estrato 1 & Estrato 2 & Estrato 3 & Estrato 4 & Estrato 5 & Estrato 6 \\
\hline Televisión & 93 & 94 & 94 & 94 & 93 & 94 \\
\hline Radio & 65 & 68 & 68 & 71 & 69 & 72 \\
\hline $\begin{array}{l}\text { Revistas } \\
\text { independientes }\end{array}$ & 26 & 37 & 47 & 62 & 75 & 80 \\
\hline Prensa & 33 & 30 & 35 & 43 & 49 & 53 \\
\hline Internet & 12 & 23 & 33 & 61 & 70 & 79 \\
\hline Cine & 2 & 3 & 6 & 13 & 14 & 18 \\
\hline
\end{tabular}

Fuente: ACIM (2010)

En el otro extremo del análisis, como ya dijimos, el consumo de televisión y radio no hace prácticamente ninguna diferencia entre los estratos sociales. El otro medio que hace una diferencia profunda entre estratos es internet, que se supone es el democratizador de la comunicación mediática. Mientras que en el estrato seis 
se consume más internet que radio y se acerca a la televisión, en el estrato uno la diferencia entre consumo de televisión e internet es casi de ocho a uno. La diferencia en el consumo de internet entre el estrato uno y el seis es de más de seis veces, y entre los estratos bajos ( 1 y 2) y los altos (5 y 6) agregados es mayor a cuatro veces. Esto, desde luego, tiene que ver con dos características ya mencionadas de internet: es de pago y exige competencias alfabéticas.

Algo parecido se puede decir de las revistas independientes. En los estratos altos se consumen más que la radio, y se acercan al consumo de televisión. En el estrato 1, la diferencia entre consumo de televisión y revistas es de casi cuatro a uno. La diferencia en el consumo de revistas entre los estratos altos agregados y la de los bajos también agregados es de dos veces y media a favor de los primeros. Esto se debe a que la mayoría de las revistas, no las más vendidas, son especializadas, son alfabéticas y tienen un precio de mercado.

En resumen, lo que preocupa de todo este panorama es que siguen siendo los mismos alfabetizados, los de altos ingresos, los que tienen consumos culturales que les permiten contrastar los relatos de la televisión y de la radio, que son casi la fuente exclusiva de información y entretenimiento para los estratos más pobres.

\section{EsBozo DE CONCLUSIÓN}

Si la televisión es la que tiene, junto con la radio, el cuasimonopolio del relato de la nación, y si los estratos más desfavorecidos de la población, que son la mayoría, no consumen ningún otro medio, quiere decir que el concepto básico de nación se está haciendo desde la televisión. Pero si miramos quienes cuasimonopolizan la audiencia, encontramos que no son ni el Estado ni mucho menos los grupos alternativos, sino, de lejos, las empresas privadas tanto de televisión como de radio, nacionales y extranjeras. En consecuencia, el relato de la nación no alcanza a ser siquiera el oficial, sino mucho menos que eso: el empresarial. Ello significa, en rigor, que la esfera pública no existe y que la educación mediática no se dirige a los ciudadanos sino a los consumidores; por tanto, no es tan importante la nación como el mercado. 
Desde luego, esto hace legítimo el discurso antiestatal y privatizador, como corresponde a los intereses del capital. El concepto de esfera pública en la que los particulares discuten asuntos públicos, distintos a sus asuntos privados (Habermas, 1999), pierde aquí su contenido democrático, pues en rigor los medios privados han llevado la discusión al mero reclamo publicitario (publicidad comercial) o a la mera propaganda política (Habermas, 1994). En efecto, si son la televisión y la radio las únicas fuentes de información para los estratos económicamente más pobres (que son más del $60 \%$ de la población), quiere decir que la esfera pública se reduce a aquellos que sí consumen otros medios en casi igual medida que la radio y la televisión, como ocurre con el alto consumo de cine, internet y revistas independientes en los estratos altos. Las diferencias entre los estratos altos y bajos en cuanto al consumo de internet lo que está mostrando es que, al contrario de lo que piensan los tecnoutopistas, la esfera pública no se está ampliando, sino que se está estratificando y va quedando reducida a los segmentos más privilegiados de la sociedad, pues son ellos los que disponen de alternativas informativas distintas a la radio y la televisión.

\section{REFERENCIAS}

Asociación Colombia de Investigación de Medios (ACIM) (2010). Estudio General de Medios. Recuperado de http://www.acimcolombia.com/Publico/WF_EstudiosDet. aspx?EST_CODIGO=11

Anderson, B. (2005). Comunidades imaginadas. Reflexiones sobre el origen y la difusión del nacionalismo. México: Fondo de Cultura Económica.

Asocel (2010). Colombia 2009 cerró con 42.025.520 abonados móviles con líneas activas. Recuperado de http://www.asocel.org.co/prensa.php

Castañeda, Y., Romero, M., Rodríguez, S. y Torres, D. (2010). Informe sobre TDT. Seminario Educación, Tecnología y Cultura. Bogotá: Universidad Pedagógica Nacional, Maestría en Educación.

Consorcio Canales Nacionales Privados (CCNP) (2010). Consorcio Canales Nacionales Privados. Recuperado de http://www.abcpublicitario.com/medios/empresa/34504 
Comisión Nacional de Televisión (CNTV) (2009). Informe sectorial de televisión 2009. Recuperado de http://www.cntv.org.co/cntv_bop/

CNTV (2010a). Concepto 93 de 2010. S. 1.

CNTV (2010b). Módulo de televisión: Estudio General de Medios (EGM), segunda ola 2010 (II-2010). Recuperado de http://www.cntv.org.co/cntv_bop/

Comisión de Regulación de Comunicaciones (CRC) (2009a). Informe trimestral de conectividad. Recuperado de www.crcom.gov.co

CRC (2009b). Informe sectorial de telecomunicaciones. Recuperado de http:// www.crcom.gov.co

Departamento Administrativo Nacional de Estadísticas (DANE) (2009). Indicadores Básicos de Tecnologías de la Información y la Comunicación TIC. Uso y penetración de TIC en Hogares y personas de 5 años y más. Bogotá: Autor.

Desde Abajo (2010). Bogotá. Julio 26, n.o 159.

Dinero (2010, 29 de mayo). Cinco mil empresas. Recuperado de http://www.dinero.com/ edicion/350

Golding, M. y Murdock, G. (2000). Culture, communications, and political economy. En J. Curran y M. Gurevitch. Mass media and society. Londres: Arnold.

Habermas, J. (1994). Historia y crítica de la opinión pública. México: Gustavo Gili.

Habermas, J. (1999). The public sphere. En P. Marris y S. Tornham. Media studies. A reader (pp. 92-97). Edimburgo: Edinburgh University Press.

Ministerio de Comunicaciones (s. f.). Impacto socioeconómico de la implementación de la televisión digital terrestre en Colombia. Recuperado de http://web.presidencia.gov.co/sp/2008/agosto/28/estandar.pdf

Ministerio de Cultura (2010). Radios universitarias. s. 1. 
Ministerio de las Tecnologías de la Información y la Comunicación (2010a). Informe trimestral de telefonía móvil, abril-junio. Recuperado de http://archivo.mintic.gov.co/mincom/faces/index.jsp?id=5508

Ministerio de las Tecnologías de la Información y la Comunicación (2010b). Informe trimestral de conectividad. Recuperado de http://archivo.mintic.gov.co/mincom/documents/ portal/documents/root/informes $\% 20 \mathrm{del} \% 20$ sector/informes $\% 20 \mathrm{de} \% 20$ conectividad/ informedeconectividad1t-2010.pdf

Ministerio de las Tecnologías de la Información y la Comunicación (2010c). Concesionarios del servicio de radiodifusión sonora comercial en Frecuencia Modulada. S.l.

Ministerio de las Tecnologías de la Información y la Comunicación (2010d). Concesionarios del servicio de radiodifusión sonora de interés público en frecuencia modulada. S. 1.

Narváez, A. (2002). Puentes tecnológicos, abismos sociales. Manizales: Ediciones Universidad de Manizales.

Narváez, A. (2010). Educación, comunicación y capitalismo cultural (tesis doctoral). Bogotá: Universidad Pedagógica Nacional.

Pachón, A. y Ramírez, M. T. (2008). La infraestructura de transporte en Colombia durante el siglo XX. Bogotá: Fondo de Cultura Económica.

Radio Cadena Nacional (RCN) (2009). Recuperado de en http://historiadelaradioencolombia.blogspot.com/2009/09/rcn-radio-cadena-nacional-60-anos-de.html

Semana (2010, 26 de abril). Las 100 empresas más grandes de Colombia. Semana, 1460. Bogotá.

Superintendencia de Sociedades (2010). Estados financieros al 31 de diciembre de 2009. Recuperado de http//sirem.supersociedades.gov.co 